\title{
About the genetics of pulmonary emphysema
}

Key words: genetic investigation methods, candidate genes, prediction, detection of pulmonary emphysema, chronic obstructive pulmonary disease, GSTM1, GSTT1, MMP9, CYP2A6, NAT2 genes.

Ключевые слова: генетические методы исследования, гены-кандидаты, прогнозирование, диагностика эмфиземы легких, хроническая обструктивная болезнь легких, гены GSTM1, GSTT1, MMP9, CYP2A6, NAT2.

Генетика эмфиземы легких (ЭЛ) до сих пор изучена недостаточно, однако, наверное, именно результатам генетических исследований предстоит ответить на вопросы: в каких случаях ЭЛ является исходом такого распространенного мультифакторного заболевания, как хроническая обструктивная болезнь легких - ХОБЛ (и почему только у $20 \%$ курильщиков развивается ХОБЛ, ЭЛ), а в каких ситуациях - это редкая патология (болезнь Дауна, синдром Маклеода, синдром Марфана, проявление коллагенопатии и др.)? Почему ЭЛ может иметь разную локализацию по современной классификации и, возможно, разные механизмы развития и доступна ли разработка критериев к разным индивидуальным видам лечения ЭЛ, включая своевременную хирургическую помощь?

Не следует забывать, что основная цель генетики это клиническое применение. Содружество генетиков и клиницистов должно приносить результаты. Так проблема тяжелого дефицита альфа-1-антитрипсина (ААТ), вклад которой в ЭЛ составляет 1-2 \%, уже не стоит остро. Роль генетических факторов при заболевании доказана, разрабатываются новые подходы лечения в эксперименте и на людях.

В основном исследователи рассматривают ЭЛ как исход ХОБЛ, что лишний раз подчеркивает актуальность проблемы, учитывая растущие распространенность и летальность при ХОБЛ во всем мире.

Как известно, ХОБЛ - это полигенное (мультифакторное) заболевание, т. е. широко распространенное, в этиологию которого вносят вклад как наследственные, так и средовые факторы. Пожизненный риск (lifetime risk) ХОБЛ в западных популяциях оценивается в $60 \%$ [1].

Для изучения генетических основ ЭЛ и ХОБЛ необходимо определять фенотип (наблюдаемые признаки заболевания) и затем классифицировать пациентов на тех, кто имеет данный фенотип, и тех, у кого он отсутствует. Серьезным препятствием в изучении факторов наследственности при ХОБЛ считается то, что лишь небольшой процент случаев может быть связан с дефектом одиночного гена или одиночным фактором внешней среды, но в большинстве случаев заболевание вызывается взаимодействием многих генов и факторов внешней среды. Это определяет необходимость комплексного подхода и к изучению генетических основ ХОБЛ и ЭЛ с использованием новых методологических подходов.

Наряду с применением методов классической генетики (близнецовые исследования, генеалогический анализ, семейные исследования, анализ генетических ассоциаций и др.) в генетике мультифакторных заболеваний происходит постоянное обновление подходов и методов. Например, полимеразная цепная реакция (ПЦР), которая обладает высокой специфичностью и не потеряла своей актуальности и диагностической ценности, относится уже к рутинным методам, дающим качественную характеристику. В то же время ПЦР в режиме реального времени (real time) может дать количественную характеристику. В клинических целях это может быть использовано для оценки вирусной или бактериальной нагрузки в крови (гепатит C, B, герпес, бактериальные инфекции). Так, используя ПЦР в режиме реального времени, можно оценить бактериальную колонизацию слизистых. При обычной ПЦР может быть выявлен ряд инфекций, но необходимо знать, в каком количестве эти агенты присутствуют. Допустим, Slaphylococcus aureus является специфическим ответом на ПЦР, и ПЦР в режиме реального времени дает количественную характеристику его титра. Если концентрация высока, целесообразно рекомендовать лечение, а если не слишком - целесообразно наблюдение в динамике. При анаэробной инфекции посредством ПЦР выявляются анаэробы, а при проведении количественной ПЦР в режиме реального времени можно дать их количественную характеристику. Если анаэробов больше, чем аэробов, патология имеется.

Относительно новым является метод микрочипов по оценке экспрессии генов (gene expression microarrays). Он позволяет одновременно исследовать экспрессию нескольких сотен генов, поскольку современное оборудование делает возможным нанесение большого числа зондов на 1 чип (пластину). В дальнейшем производят гибридизацию исследуемой комплементарной ДНК (кДНК) с нанесенными зондами. Данная технология позволяет сравнивать 
функционирование генома в норме и при патологии, и по возможности выделять изменения в экспрессии генов в процессе развития заболевания.

Широко используется метод секвенирования (sequence - последовательность). Его задача - определение точной последовательности нуклеотидов, т. е. мономеров, из которых состоят нуклеиновые кислоты (секвенирование всей ДНК было проведено в программе "геном человека"). Одиночные нуклеотидные полиморфизмы (ОНП или SNPs - single nucleotide polymorphism(s)) - это $\geq 1$ нуклеотидной замены или выпадения / вставки нуклеотида. Если ОНП известны, их идентифицируют посредством ПЦР с рестрикционным анализом; если присутствие OHП (SNPs) в гене предполагается - проводят их поиск, например методом секвенирования. В настоящее время существуют электронные базы (например, GenBank, HapMap), включающие в себя как геномные последовательности, характерные для нормы, так и генетические варианты генов, ассоциированные с различными патологиями. В основном метод секвенирования используется для поиска новых мутаций при различных патологиях. При этом секвенируют протяженные участки ДНК локусов, ранее ассоциированных с заболеванием.

Анализ сцепления (genome-wide linkage analysis) (семейные исследования) связан с использованием множественных маркеров, распространенных по всему геному. При этом определяют, сцеплен ли данный хромосомный локус с заболеванием внутри разветвленной родословной в одной конкретной семье. Если в хромосомном локусе, показавшем сцепление с заболеванием, расположены ранее описанные гены, то выбирают гены, продукты которых могут быть вовлечены в патологический процесс. Далее в разветвленных семьях проводят сопоставление нуклеотидной последовательности выбранных генов у лиц с патологией и без патологии с целью выявления ОНП, ассоциированных с заболеванием.

Существуют и более новые технологии, такие как полное сканирование генома (genome-wide association studes), при котором поиск генетических маркеров, ассоциированных с заболеванием, проводится по описанному выше принципу, однако последовательности генов сопоставляются не внутри семей, а между группами сравнения (лица с заболеванием и без). Такой подход может приводить к идентификации новых генов-кандидатов ХОБЛ, которые далее могут быть использованы для исследований in vivo и in vitro.

Недавно с помощью анализа сцепления (genomewide linkage analysis) было выявлено 2 гена, ассоциированных с ХОБЛ: TGF- $\beta_{1}$ (трансформирующий фактор роста- $\beta_{1}, 2004$ г.) и SERPINE2 (serpin pepetidasae inhibitor E2, 2006 г.). Однако, как и в исследовании других генов-кандидатов ХОБЛ, даже эти достоверно идентифицированные ассоциации генетических маркеров заболевания не всегда выявляются в повторных исследованиях (табл. 1). Проблемы с воспроизводимостью в генетических исследованиях, особенно при таких гетерогенных заболеваниях, как
ХОБЛ и ЭЛ, могут быть объяснены (возможные причины будет рассматриваться далее).

Тем не менее, несмотря на возможные трудности при выявлении генетических маркеров, ассоциированных с ХОБЛ, и воспроизводимости полученных ассоциаций на примере других популяций, генетика ЭЛ и ХОБЛ - бурно и быстроразвивающаяся наука. И этому есть объяснение. Во-первых, формирование гено-фенотипического портрета пациента с ЭЛ или ХОБЛ дает возможность ранней диагностики заболевания и прогнозирования риска до развития клинических симптомов, выхода на первичную профилактику, определения групп риска, профориентации и т. Д.

Во-вторых, генетика обеспечивает уникальную модель для изучения патогенеза ЭЛ и ХОБЛ. Традиционно лабораторные исследования или опыты на моделях животных сфокусированы на 1 гене или его комбинациях (с идентифицированным кодируемым белком) и основываются на имеющихся данных о механизмах патогенеза ХОБЛ и ЭЛ. Открытые таким образом в эксперименте гены-кандидаты должны быть подтверждены исследованиями на человеке. Методы генетики человека располагают необходимыми для этого подходами и могут обеспечить подтверждение экспериментальных открытий. Однако необходимо подчеркнуть, что современные классические методы генетики, например анализ сцепления (genome-wide linkage analysis), проводимый при семейных исследованиях и более новые технологии, такие как сканирование генома (genomewide association studes), проводимые без семей и без первичного анализа патогенеза заболевания (сначала поиск генов-маркеров, а затем их исследование), значительно расширяют и упрощают возможности поиска.

В-третьих, это новые подходы к лечению, в т. ч. с вероятным учетом индивидуальных особенностей. Использование промежуточного фенотипа (не полного фенотипа заболевания, а фенотипа по каким-то определенным выбранным критериям) позволяет проводить поиск ассоциаций не только в общей группе больных. Выделяют различные подгруппы, например в зависимости от важных показателей функции внешнего дыхания (ФВД) или от показателей, полученных с использованием компьютерной томографии, особенно с высоким разрешением, денситометрии и др. Использование новых генетических подходов, обладающих большим потенциалом в определении новых генов, ассоциированных не только с заболеванием, но с тяжестью, особенностью его течения, а также с ответом на проводимое лечение и др., может помочь в разработке новых фармакогенетических подходов с учетом генетического статуса пациента.

Примером преимущества интегрирования различных методов исследования явились, в частности, результаты, полученные группой исследователей из Бостона. Они выявили несколько генетических маркеров, ассоциированных с ХОБЛ [2-5]. Так, при анализе генома в семьях с ранним началом ХОБЛ 
была выявлена область на хромосоме 2q, ассоциированная с таким показателем ФВД, как индекс Тиффно [3, 4]. Результаты указывали на потенциальную важность генов в этой области. В дальнейшем был идентифицирован ген SERPINE2, локализованный на хромосоме 2q [6, 7]. Показательно, что роль нового гена SERPINE2 первоначально была изучена у мышей [8], когда была показана его высокая экспрессия в процессе развития легких (чиповые технологии мРНК). Известно, что гены, продукты которых участвуют в дифференцировке или процессах репарации (заживления) легких, могут предрасполагать к ЭЛ, влияя на размеры воздушных и альвеолярных пространств. Затем экспрессия гена SERPINE2 была ассоциирована с показателем теста Тиффно в исследованиях эмфизематозных участков легкого, взятых от пациентов после оперативного вмешательства по поводу ЭЛ (NETT) [9]. Результаты, полученные на мышах и в образцах удаленных эмфизематозных участков легкого у человека, были проанализированы $[10,11]$ и интегрированы в исследованиях по поиску аллельных вариантов ОНП.

Y.Zhu et al. прогенотипировали 25 ОНП в гене SERPINE2 и обнаружили, что 6 из них достоверно ассоциированы с ХОБЛ и спирометрическими показателями легких [12]. Далее было подтверждено, что 5 из этих 6 ОНП были ассоциированы с обструктивными нарушениями в группе исследованных "случай-контроль" в Норвегии [8]. В результате были

идентифицированы гаплотипы, повышающие риск ХОБЛ $[12,8]$. И, хотя роль этого гена еще должна быть уточнена, это исследование продемонстрировало удачную интеграцию методов изучения экспрессии гена и исследований по ассоциации его ОНП с фенотипическими параметрами заболевания.

В этих же исследованиях было выявлено, что показатели объема форсированного выдоха за 1-ю с $\left(\mathrm{OФB}_{1}\right)$ ассоциированы с маркерами, расположенными на хромосоме 12p и 8p [13]. Маркеры на хромосоме 19q также показали ассоциацию с количественными и качественными признаками в семьях ХОБЛ $[14,15]$. В этих областях оказались локализованными гены: SFTPC (SP-C) белок сурфактанта C, CTSB катепсин B, A2M $\alpha_{2}$-макроглобулин, LTBP 4 белок, связывающий латентный трансформирующий фактор роста 4 и недавно открытый ген TGF- $\beta_{1}$ (табл. 2). Анализ по поиску генов-кандидатов, расположенных в этих локусах, продолжается.

В ряде работ распределение аллелей или генотипов $\geq$ ОНП проводили у пациентов ХОБЛ в сравнении с группой контроля. Гены, варианты которых были ассоциированы с ХОБЛ и ЭЛ в $\geq 2$ исследованиях (значимые гены), представлены в табл. 1.

Приведем результаты кооперации исследований при изучении генетики ЭЛ и ХОБЛ, опубликованные в одной из последних работ [78]. Были использованы результаты по 3 группам исследованных. Дизайн и группы представлены на рисунке. Состав обследованных был следующим:

Таблица 1

Гены-кандидаты, за исключением $\alpha_{1}$-ИП (SERPINA1), с исследованиями, подтверждающими их ассоциаци с ХОБЛ и ЭЛ

\begin{tabular}{|c|c|c|c|}
\hline Гены & $\begin{array}{l}\text { Изначально получен- } \\
\text { ные ассоциации }\end{array}$ & $\begin{array}{l}\text { Подтверждение полу- } \\
\text { ченных ассоциаций }\end{array}$ & $\begin{array}{l}\text { Исследования, не подтверждающие } \\
\text { ассоциации }\end{array}$ \\
\hline$\alpha_{1}$-antichymotrypsin (SERPINA3) & Poller, $1992[6,17]$ & Ishii, 2000 [18] & Sandford, 1998 [19]; Benetazzo, 1999 [20] \\
\hline$\beta_{2}$-adrenergic receptor (ADRB2) & Ho, 2001 [21] & Hegab, 2004 [22] & Joos, 2003 [23]; Brogger, 2006 [24] \\
\hline Defensin $\beta_{1}$ (DEFB1) & Matsushita, 2002 [25] & $H u, 2004[26]$ & Wallace, 2006 [27]; Hersh, 2006 [28] \\
\hline \multirow[t]{3}{*}{ Microsomal epoxide hydrolase (EPHX1) } & Smith, 1997 [29] & Sandford, 2001 [30]; & Yoshikawa, 2000 [33]; Takeyabu, 2000 [34]; \\
\hline & & Xiao, 2004 [31];] & Yim, 2000 [35] \\
\hline & & DeMeo, 2007 [32 & \\
\hline Vitamin D binding protein (GC) & Horne, 1990 [36] & $\begin{array}{l}\text { Schellenberg, } 1998 \text { [37]; } \\
\text { Ishii, } 2001 \text { [39]; } \\
\text { Ito, } 2004 \text { [39] }\end{array}$ & $\begin{array}{l}\text { Kauffmann, } 1983 \text { [40]; Kasuga, } 2003 \text { [41]; } \\
\text { Sandford, } 2001 \text { [42] }\end{array}$ \\
\hline \multirow[t]{2}{*}{ Glutathione S-transferase M1 (GSTM1) } & Harrison, 1997 [43] & Baranova, 1997 [44]; & Yim, 2000 [46]; He, 2002 [47] \\
\hline & & Cheng, 2004 [45] & \\
\hline Glutathione S-transferase pi (GSTP1) & Ishii, 1999 [48] & $\mathrm{He}, 2002[47]$ & Yim, 2002 [49]; Cheng, 2004 [45]; Xiao, 2004 [31] \\
\hline \multirow[t]{2}{*}{ Heme oxygenase (HMOX1) } & Yamada, $2000[50]$ & Guenegou, 2006 [51]; & $\mathrm{He}, 2002$ [47] \\
\hline & & Nakayama, 2006 [52] & \\
\hline Matrix metallopeptidase-9 (MMP9) & Minematsu, 2001 [53] & Zhou, 2004 [54] & Joos, 2002 [55] \\
\hline Serpin peptidase inhibitor E2 (SERPINE2) & DeMeo, 2006 [8] & Zhu, 2007 [12] & Chappell, 2006 [56] \\
\hline Extracellular superoxide dismutase (SOD3) & Juul, 2006 [57] & Young, 2006 [58] & \\
\hline Surfactant protein B (SFTPB) & Guo, 2001 [59] & Seifart, 2002 [60] & \\
\hline \multirow[t]{3}{*}{ Transforming growth factor- $\beta_{1}\left(\right.$ TGF- $\left.\beta_{1}\right)$} & Wu, $2004[61]$ & Celedon, 2004 [14]; & Yoon, 2006 [64]; Ogawa 2007 [65] \\
\hline & & Su, 2005 [62]; & \\
\hline & & Van Diemen, 2006 [63] & \\
\hline \multirow[t]{4}{*}{ Tumor necrosis factor (TNF) } & Huang, 1997 [66] & Sakao, 2001 [67]; & Higham, 2000 [69]; Ishii, 2000 [70]; Patuzzo, 2000 [71]; \\
\hline & & Matheson, 2006 [68] & Sandford, 2001 [42]; Ferrarotti, 2003 [72]; \\
\hline & & & Chierakul, 2005 [73]; Hegab, 2005 [74]; Jiang, 2005 [75]; \\
\hline & & & Seifart, 2005 [76]; Brogger, 2006 [24]; Ruse, 2007 [77] \\
\hline
\end{tabular}


- Boston Early-Onset COPD Study - Бостоновская группа семей с ранним началом (до 53 лет) и тяжелым течением ХОБЛ $\left(\mathrm{OФВ}_{1}<40\right.$ \% долж.) у пробандов, без дефицита ААТ [6]. Подразумевалось, что эти больные имеют более значительный генетический вклад в развитие ХОБЛ и ЭЛ, чем больные, диагностируемые в позднем возрасте.

- Framingham Heart Study - Фраммингамское исследование по предрасположению к атеросклерозу. Это большая популяционная группа ( 5000 человек) начинала набираться с 1948 г. с целью выяснения причин роста сердечно-сосудистых заболеваний. В нее вошли лица в возрасте от 30 до 62 лет, которые на момент начала наблюдения были здоровы и контрольные осмотры которых проводились раз в 2 года. В 1971 г. в эту же группу обследованных набрали их детей, и в настоящее время начат набор их внуков. Таким образом, популяционная группа состоит из 3 поколений в семьях. В этой группе выделены здоровые некурильщики и курильщики со стажем $\geq 10$ лет с указанием индекса курения. В 3 поколениях были изучены ассоциации десяти показателей ФВД (в \% долж.) с большим числом генетических факторов и подтверждена генетическая детерминированность ряда таких важных показателей ФВД, как ОФВ 1 , индекс Тиффно, пиковая скорость выдоха в значении 25-75\% долж. [79]

- NETT, Lung health Study - мультицентровое рандомизированное контролируемое исследование по лечению ЭЛ в группах пациентов (1 218 человек). Учитывалась эффективность совместного хи-

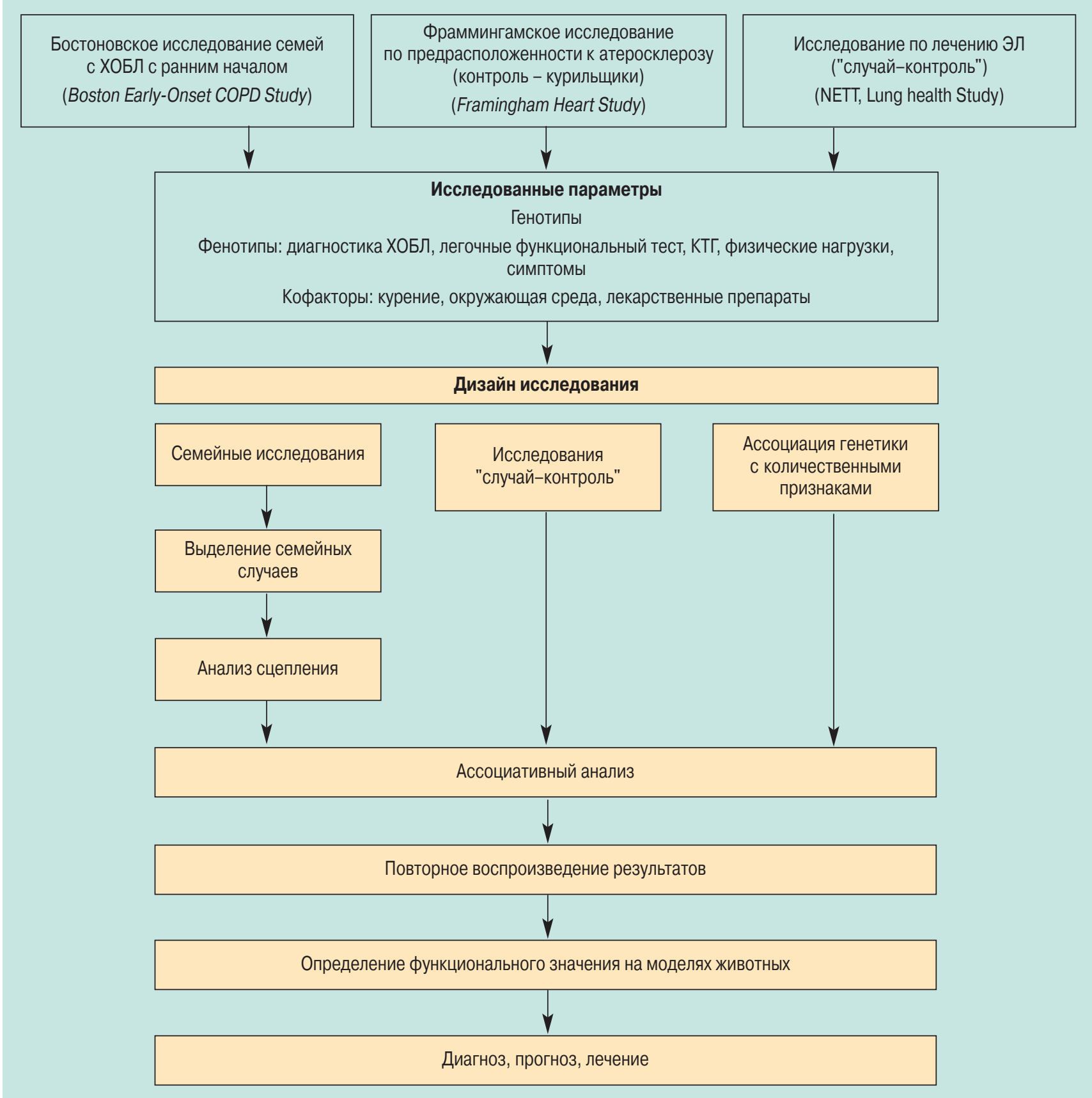

Рисунок. Схема интеграции исследований в области генетической эпидемиологии ХОБЛ Примечание: NETT - национальные исследования по лечению ЭЛ; КТГ - кардиотокография. 
рургического лечения с медикаментозным и группа только с медикаментозным лечением.

Чтобы системно проверить воспроизводимость результатов опубликованных ранее работ по генетическим ассоциациям при ХОБЛ и ЭЛ, группа из Бостона изучала 29 аллельных вариантов 12 генов-кандидатов ХОБЛ [80]. Генотипирование вариантов проводилось параллельно в 2 сравниваемых исследованиях: 1) Бостоновская группа; 2) исследование "случай-контроль", включавшее в себя 304 пациента с ЭЛ и тяжелой обструкцией из обследованных NETT и 441 курильщика без обструкции из исследованных Normative Aging Study ("нормальное старение") [81].

В Бостоновском исследовании было выявлено, что полиморфизмы в 3 генах достоверно ассоциировались с количественными и качественными спирометрическими показателями при ХОБЛ, а именно:

- ОНП (SNP) промоторной области гена (TNF)- $\alpha$ (фактор некроза опухоли- $\alpha$ );

- замена в кодирующей области гена белка сурфактанта B (SFTB) Thr 131 Ile (триптофан 131 на изолейцин);

- полиморфные повторы, расположенные рядом с геном гем-оксигеназы 1 (HMOX1).

В исследовании "случай-контроль":

- ОНП в промоторной области гена (TNF)- $\alpha$ не ассоциировался с ХОБЛ;

- подтверждена вариация в кодирующей области гена белка сурфактанта В (SFTB) Thr 131 Ile, которая была достоверно ассоциирована с заболеванием при учете фактора курения;

- показана достоверная ассоциация с ХОБЛ для одного из вариантов гена НМОХ1.

И только в исследовании "случай-контроль" (не в Бостоновской группе) ОНП кодирующей области гена микросомальной эпоксидгидролазы 1 (ЕРНХ1) His 139 Arg (гистидин 139 на аргинин), называемый "быстрым" аллелем, по его ассоциации с высокой активностью фермента имел достоверную значимость.

Такие результаты серьезных генетических исследований могут служить примером трудностей в воспроизводимости достоверных ассоциаций на других группах обследованных (повторяемости) результатов. Это заставляет предположить, что причина может заключаться не только в сложности генетического эксперимента [82, 83], но и в изучении разных фенотипов ЭЛ и ХОБЛ, что связано, вероятно, с генетической гетерогенностью заболевания, этническими, популяционными особенностями, немногочисленностью групп обследованных, ошибками дифференциальной диагностики клинически близких патологий и т. д. [84].

Поэтому, чтобы избежать подобных неточностей, допустимо применять ассоциативный анализ не с самим заболеванием, а с каким-то его количественным признаком - "промежуточным фенотипом". Это могут быть ОФВ 1 , индекс Тиффно, нагрузочные пробы, сроки начала болезни, результаты кардиотокографии (КТГ) и др. В подобных исследованиях использование количественных признаков (промежу- точного фенотипа ХОБЛ и ЭЛ) также помогает в поиске генов-кандидатов ХОБЛ и ЭЛ и их подтипов.

Примером подхода с изучением промежуточного фенотипа может служить обследование пациентов NETT, при котором пытались сопоставить генетический статус с разным ответом пациентов на физическую нагрузку при ЭЛ. Были изучены генетические варианты 22 генов-кандидатов у 304 пациентов, входящих в исследование NETT [85]. Пациенты с ЭЛ были разделены на группы по ответу на тест физической нагрузки, который определялся при эргометрическом тесте и пробе с 6-минутной ходьбой. Учитывались выраженность одышки, индекс массы тела, показатели функции внешнего дыхания, включая диффузионную способность легких и др. [86]. Было обнаружено, что генетические варианты 4 генов - EPHX1, SFTPB, TGF- $\beta_{1}$, протеин-4-связывающий (TGF- $\beta_{1}$ ) были ассоциированы с ответом на физическую нагрузку у пациентов с ЭЛ. Ассоциация OHП в промоторной области гена TGF- $\beta_{1}$ с симптомами одышки была подтверждена в Бостонском исследовании у лиц с ранним началом ХОБЛ [78].

Другим примером изучения промежуточного фенотипа явились исследования, при которых учитывали, что генетические факторы могут влиять на локализацию ЭЛ не только у лиц с недостаточностью ААТ и предположили, что КТГ с высоким разрешением и денситометрия тоже могут служить количественными маркерами тяжести ЭЛ.

I.Ito et al., работы которых явились одними из лидирующих по изучению генетических ассоциаций с данными КТГ с высоким разрешением и денситометрией легких, прогенотипировали ОНП в промоторной области гена ММР9(C-1562Т) у 84 пациентов с ХОБЛ (Япония) и 85 контрольных курильщиков без обструкции [87]. Хотя не было обнаружено ассоциации аллеля Т с ХОБЛ, данный аллель был ассоциирован с верхнедолевой ЭЛ диагностированной с помощью КТГ с высоким разрешением.

В исследовании NETT верхнедолевая локализация ЭЛ является важным показанием к хирургическому лечению [88]. D.DeMeo et al. исследовали генетические варианты 22 генов-кандидатов у 282 пациентов ЭЛ также в сопоставлении с данными КTГ в NETT исследовании [32]. Генетические варианты генов глутатион-S-трансфераза pi (GSTP1) и микросомальный эпоксид гидролазы 1 (ЕРНX1) в их исследовании были достоверно ассоциированы с локализацией ЭЛ, полученной при денситометрии. Варианты в кодирующей области генов GSTP1 Ile105Val (изолейцин 105 на валин) и EPHX1 His139Arg (гистидин 139 на аргинин) были ассоциированы с верхнедолевой ЭЛ. Ассоциация варианта EPHX1 His139Arg с верхнедолевой ЭЛ была подтверждена в группе обследованных Normative Aging Study ("нормальное старение").

Итак, было показано, что КТГ легких с высоким разрешением и денситометрией, которые используются для оценки тяжести, локализации и распространенности ЭЛ, могут служить промежуточным фенотипом ЭЛ (количественным параметром), 
а сопоставление результатов с генетическими данными открывает путь к масштабным генетико-эпидемиологическим исследованиям. Кроме того, такого рода подходы с интеграцией генетических исследований и КТГ диагностики с денситометрией важны в клинике для определения показаний к хирургическому лечению ЭЛ. Эти интегрированные исследования только начинаются.

Важно, что ответ на медикаментозную терапию, включая длительную кислородотерапию и хирургическое вмешательство, может также быть обусловлен генетической предрасположенностью. В этой связи уже проводятся исследования, при которых изучаются особенности ДНК у лиц, вКлюченных в клинические испытания по лечению ХОБЛ и ЭЛ, и это является необходимым подходом для исследования механизмов фармакогенетики.

\section{Редкие варианты в генетике ХОБЛ}

Другой путь понимания генетики ХОБЛ связан с уроками, которые можно извлечь из изучения моногенных заболеваний, таких как болезнь соединительной ткани, связанная с аномалией развития (дряблая, легко оттягиваемая кожа и др.) - Cutis laxa. При аутосомно-доминантном варианте болезни были выявлены мутации, связанные с геном, кодирующим эластин. Секвенирование 6 последних экзонов эластина у 116 человек из Бостоновской популяции с ранним началом ХОБЛ позволило открыть видимо новый вариант мутации у 1 человека [89]. Далее обследовали всех его родственников, и все взрослые но- сители этой мутации имели признаки бронхиальной обструкции. Затем в группе NETT 318 человек с ЭЛ тоже были прогенотипированы (по этому варианту), и мутация была найдена у 1,25 \% больных ЭЛ. В контрольной группе курильщиков этот показатель составил 0,55 \%. В дальнейшем клеточные исследования по оценке влияния этого гена на эластин продемонстрировали, что этот вариант влияет на чувствительность к протеолизу, а именно на сборку волокон эластина.

В отличие от Cutis laxa, ЭЛ не часто ассоциируется с другими заболеваниями соединительной ткани, такими как синдром Элерса-Данлоса и синдром Марфана.

В заключение следует подчеркнуть, что основной областью научного интереса при изучении ЭЛ и ХОБЛ является исследование профилей экспрессии генов с использованием РНК или кДНК микрочипов. Данный подход представляется перспективным. Дальнейшие исследования по интеграции методов генной экспрессии и генной вариабельности, скорее всего, приведут к открытию дополнительных генов-кандидатов ЭЛ и ХОБЛ.

Таковы основные подходы и методы генетических исследований на сегодняшний день, по литературным данным.

В табл. 2 приведены некоторые изучаемые при ЭЛ и ХОБЛ гены, результаты исследований по которым не вошли в предлагаемый обзор.

Среди отечественных авторов проблемам генетики ХОБЛ посвящены работы академика В.П.Пузырева [93, 94], проф. В.А.Вавилина [90], проф. Т.В.Вик-

Таблица 2

Некоторые гены, изучаемые при ЭЛ и ХОБЛ

\begin{tabular}{|c|c|c|c|}
\hline Ген & Русское название & Английское название & Локализация \\
\hline \multicolumn{4}{|l|}{ 1. TGF $\beta$} \\
\hline 1.1. $\operatorname{TGF} \beta_{1}$ & Трансформирующий фактор роста бета-1 & Transforming growth factor, beta 1 & $19 q 13.1$ \\
\hline 1.2. $\mathrm{TGF} \beta_{2}$ & Трансформирующий фактор роста бета-2 & Transforming growth factor, beta 2 & $1 \mathrm{q} 41$ \\
\hline 1. 3. $\operatorname{TGF} \beta_{3}$ & Трансформирующий фактор роста бета-3 & Transforming growth factor, beta 3 & $14 q 24$ \\
\hline \multicolumn{4}{|c|}{ 2. Гены - регуляторы сигнализации TGF $\beta$} \\
\hline 2.1. Lap & Латентно-ассоциированный пропептид & Latency-associated propeptide & - \\
\hline 2.2. LTBP 1 & $\begin{array}{l}\text { Белок, связывающий латентный трансфор- } \\
\text { мирующий фактор роста-1 }\end{array}$ & $\begin{array}{l}\text { Latent transforming growth factor beta } \\
\text { binding protein } 1\end{array}$ & 2p22-p21 \\
\hline 2.3. LTBP 3 & $\begin{array}{l}\text { Белок, связывающий латентный трансфор- } \\
\text { мирующий фактор роста-3 }\end{array}$ & $\begin{array}{l}\text { Latent transforming growth factor beta } \\
\text { binding protein } 3\end{array}$ & $11 q 12$ \\
\hline 2.4. LTBP 4 & $\begin{array}{l}\text { Белок, связывающий латентный трансфор- } \\
\text { мирующий фактор роста-4 }\end{array}$ & $\begin{array}{l}\text { Latent transforming growth factor beta } \\
\text { binding protein } 4\end{array}$ & $19 q 13.1-q 13.2$ \\
\hline 2.5. FUT8 & 1,6 $\alpha$-фукозилтрансфераза & Fucosyltransferase 8 (alpha $(1,6)$ fucosyltransferase) & $14 \mathrm{q} 24.3$ \\
\hline 2.6. Smad2 & $\begin{array}{l}\text { Сигнальный протеин-2-трансформирующего } \\
\text { фактора роста бета }\end{array}$ & Transforming growth factor-beta signaling protein 2 & $18 \mathrm{q} 21.1$ \\
\hline 2.7. Smad3 & $\begin{array}{l}\text { Сигнальный протеин-3-трансформирующего } \\
\text { фактора роста бета }\end{array}$ & Transforming growth factor-beta signaling protein 3 & $15 q 22.33$ \\
\hline 2.8. Smad4 & $\begin{array}{l}\text { Сигнальный протеин-4-трансформирующего } \\
\text { фактора роста бета }\end{array}$ & Transforming growth factor-beta signaling protein 4 & $18 \mathrm{q} 21.1$ \\
\hline \multicolumn{4}{|c|}{ 3. Другие факторы роста и колониестимулирующие факторы } \\
\hline 3.1. IGFBP-3 & Инсулиноподобный фактор роста фибробластов-3 & Insulin-like growth factor binding protein 3 & $7 \mathrm{p} 13-\mathrm{p} 12$ \\
\hline 3.2. IGFBP-7 & Инсулиноподобный фактор роста фибробластов-7 & Insulin-like growth factor binding protein 7 & $4 q 12$ \\
\hline 3.3. FGF-2 & Фактор роста фибробластов-2 & Fibroblast growth factor 2 & $4 q 26-q 27$ \\
\hline 3.4. CTGF & Соединительнотканный фактор роста & Connective tissue growth factor & $6 q 23.1$ \\
\hline 3.5. PDGF $\beta$ & Тромбоцитарный фактор роста- $\beta$ & Platelet-derived growth factor beta polypeptide & $22 q 13.1$ \\
\hline
\end{tabular}




\begin{tabular}{|c|c|c|c|}
\hline 3.6. PDGF $\alpha$ & Тромбоцитарный фактор роста- $\alpha$ & Platelet-derived growth factor alpha polypeptide & $7 \mathrm{p} 22$ \\
\hline 3.7. EGF & Эпидермальный фактор роста & Epidermal growth factor & $4 q 25$ \\
\hline 3.8. TGF $\alpha$ & Трансформирующий фактор роста- $\alpha$ & Transforming growth factor, alpha & $2 p 13$ \\
\hline 3.9. VEGF & Эндотелиальный фактора роста & Vascular endothelial growth factor & $6 \mathrm{p} 12$ \\
\hline 3.10. CSF2 (GMCSF) & $\begin{array}{l}\text { Колониестимулирующий фактор-2 (гранулоцитарно- } \\
\text { макрофагальный колониестимулирующий фактор) }\end{array}$ & Colony stimulating factor 2 (granulocyte-macrophage) & $5 q 31.1$ \\
\hline \multicolumn{4}{|l|}{ 4. Белки сурфактанта } \\
\hline 4.1. SFTPA (SP-A) & Белок сурфактанта A & Surfactant, pulmonary-associated protein A & $10 \mathrm{q} 22.3$ \\
\hline 4.2. SFTPD (SP-D) & Белок сурфактанта D & Surfactant, pulmonary-associated protein D & $10 q 22.2-q 23.1$ \\
\hline 4.3. SFTPB (SP-B) & Белок сурфактанта В & Surfactant, pulmonary-associated protein B & $2 p 12-p 11.2$ \\
\hline 4.4. SFTPC (SP-C) & Белок сурфактанта С & Surfactant, pulmonary-associated protein C & $8 \mathrm{p} 21$ \\
\hline \multicolumn{4}{|c|}{ 5. Сериновые протеазы } \\
\hline \multicolumn{4}{|c|}{ А. Нейтрофильная эластаза и гены, влияющие на ее функцию } \\
\hline 5.1. ELA2 (NE) & Эластаза 2 (нейтрофильная эластаза) & Elastase 2 (neutrophil) & $19 \mathrm{p} 13.3$ \\
\hline 5.2. MAP2K1 (MEK1) & Митогенактивированная протеинкиназа киназа-1 & Mitogen-activated protein kinase kinase 1 & $15 q 22.1-q 22.33$ \\
\hline 5.3. МАР2K2 (МЕK2) & Митогенактивированная протеинкиназа киназа-2 & Mitogen-activated protein kinase kinase 2 & $19 \mathrm{p} 13.3$ \\
\hline 5.4. MAPK3 (ERK1) & Митогенактивированная протеинкиназа-3 & Mitogen-activated protein kinase 3 & $16 p 11.2$ \\
\hline 5.5. MAPK1 (ERK2) & Митогенактивированная протеинкиназа-1 & Mitogen-activated protein kinase 1 & $22 q 11.21$ \\
\hline 5.6. SERPIN $\alpha_{1}$ & $\alpha_{1}$-антитрипсин (вариант-1) & Alpha-1-antitrypsin (member 1) & $14 q 32.1$ \\
\hline 5.7. A2M & $\alpha_{2}$-макроглобулин & Alpha-2-macroglobulin & 12p13.3-p12.3 \\
\hline \multicolumn{4}{|c|}{ Б. Другие сериновые протеиназы } \\
\hline 5.8. PRTN3 & Протеиназа 3 & Proteinase 3 & $19 p 13.3$ \\
\hline 5.9. CTSG & Катепсин G & Cathepsin G & $14 q 11.2$ \\
\hline \multicolumn{4}{|c|}{ 6. Цистеиновые протеазы } \\
\hline 6.1. CTSF & Катепсин F & Cathepsin F & $11 q 13$ \\
\hline 6.2. CTSS & Катепсин S & Cathepsin S & $1 \mathrm{q} 21$ \\
\hline 6.3. CTSL1 & Катепсин L1 & Cathepsin L1 & $9 q 21-q 22$ \\
\hline 6.4. CTSL2 & Катепсин L2 & Cathepsin L2 & $9 q 22.2$ \\
\hline 6.5. CTSK & Катепсин К & Cathepsin K & $1 q 21$ \\
\hline 6.6. CTSB & Катепсин В & Cathepsin B & 8p22 \\
\hline \multicolumn{4}{|c|}{ 7. Матриксные металлопротеиназы } \\
\hline 7.1. MMP 1 & Матриксная металлопротеиназа-1 & Matrix metallopeptidase 1 & $11 \mathrm{q} 22.3$ \\
\hline 7.2. MMP 2 & Матриксная металлопротеиназа-2 & Matrix metallopeptidase 2 & $16 q 13-q 21$ \\
\hline 7.3. MMP 9 & Матриксная металлопротеиназа-9 & Matrix metallopeptidase 9 & $20 q 11.2-q 13.1$ \\
\hline 7.4. MMP 12 & Матриксная металлопротеиназа-12 & Matrix metallopeptidase 12 & $11 \mathrm{q} 22.3$ \\
\hline 7.5. TIMP-1 & Тканевый ингибитор металлопротеиназ-1 & Tissue inhibitor of metalloprotease 1 & Xp11.3-p11.23 \\
\hline 7.6. TIMP-2 & Тканевый ингибитор металлопротеиназ-2 & Tissue inhibitor of metalloprotease 2 & $17 q 25$ \\
\hline 7.7. TIMP-3 & Тканевый ингибитор металлопротеиназ-3 & Tissue inhibitor of metalloprotease 3 & $22 q 12.3$ \\
\hline \multicolumn{4}{|c|}{ 8. Интерлейкины и TNF- $\alpha$} \\
\hline 8.1. IL-1 $\beta$ & Интерлейкин-1 $\beta$ & Interleukin-1 $\beta$ & $2 q 14$ \\
\hline 8.2. IL-4 & Интерлейкин-4 & Interleukin 4 & $5 q 31.1$ \\
\hline 8.3. IL-6 & Интерлейкин-6 & Interleukin 6 & $7 \mathrm{p} 21$ \\
\hline 8.4. IL-8 & Интерлейкин-8 & Interleukin 8 & $4 q 13-q 21$ \\
\hline 8.5. IL-18 & Интерлейкин-18 & Interleukin 18 & $11 q 22.2-q 22.3$ \\
\hline 8.6. $\operatorname{TNF} \alpha$ & Фактор некроза опухоли & Tumor necrosis factor & $6 p 21.3$ \\
\hline \multicolumn{4}{|l|}{ 9. Хемокины } \\
\hline 9.1. CCR3 & Хемокиновый рецептор (семейства С-С) 3 & Chemokine (C-C motif) receptor 3 & $3 p 21.3$ \\
\hline 9.2. CCR4 & Хемокиновый рецептор (семейства С-С) 4 & Chemokine (C-C motif) receptor 4 & $3 p 24$ \\
\hline 9.3. CCR & Хемокиновый рецептор (семейства С-С) 5 & Chemokine (C-C motif) receptor 5 & $3 \mathrm{p} 21.31$ \\
\hline 9.4. CXCR3 & Хемокиновый рецептор (семейства СХС) 3 & Chemokine (CXC motif) receptor & $\mathrm{Xq13}$ \\
\hline
\end{tabular}

торовой и ее учеников, Д.Г.Янбаевой [95], Л.З.Ахмадишиной [96], О.В.Байнак [97], Л.С.Степанищевой и Г.Л.Игнатовой [98] и др.

Остановимся на собственных данных по изучению роли наследственности в развитии и формировании ХОБЛ. Учитывая, что курение относится к традиционным экзогенным факторам риска ХОБЛ, логично предположить существование наследственной предрасположенности не только к ХОБЛ, но и к воздействию табачного дыма. Поэтому представлялось целесообразным, учитывая основные из известных звеньев патогенеза ХОБЛ, изучение полиморфизма генов-кандидатов, белковые продукты которых относятся к системам биотрансформации никотина и других ксенобиотиков и протеолиза-антипротеолиза. Анализ ген-генного взаимодействия генов I и II фазы детоксикации, матриксных металлопротеиназ, а также комплексного взаимодействия 
этих генов представлялся целесообразным для изучения формирования наследственной предрасположенности к развитию ХОБЛ у курильщиков табака.

Задачей исследования было определение у больных ХОБЛ, хроническим неспецифическим бронхитом (ХНБ) и у злостных курильщиков, не страдающих хроническими болезнями органов дыхания (БОД), проживающих в Санкт-Петербурге, частоты следующих генетических и фенотипических маркеров:

- плюс- и нуль-генотипов генов глутатион-Sтрансфераз М1 и Т1, ассоциированных с наличием (генотип GSTM1+, GSTT1+) или отсутствием (GSTM1*0 / 0, GSTT1*0 / 0) кодируемого фермента;

- аллелей гена матриксной металлопротеиназы-9 (ММР9), ассоциированных с нормальной (генотип СС) и повышенной (генотипы СТ и ТТ) экспрессией гена;

- аллелей гена NAT2, ассоциированных с быстрым (генотип RR, RS) и медленным (генотип SS) ацетилированием ариламинов;

- аллелей гена СYР2А6, ассоциированных с нормальной (генотип СYР2А6*1 / *1) и низкой (генотипы CYP2A6*1 / *2; CYP2A6*2 / *2; CYP2A6*1 / *3 и СҮР2А6*3 / *3) активностью кумарин-7-гидроксилазы, ответственной за метаболизм 60-80\% никотина.

Глутатин-S-трансфераза M1, ген - GSTM1, локализация - 1p1.13, II фаза детоксикации никотина и других ксенобиотиков; делеция 2 аллелей приводит к полному отсутствию синтеза белка - генотип $\operatorname{GSTM1}(0 / 0)$, делеция 1 аллеля приводит к снижению функции - генотип GSTM1 (1 / 0), генотип GSTM1 (1 / 1) - дикий тип с нормальной функцией.

Глутатин-S-трансфераза T1, ген - GSTT1, локализация - 22q11.2, II фаза детоксикации; делеция 2 аллелей гена приводит к полному отсутствию синтеза белка - генотип GSTT1(0 / 0), делеция 1 аллеля приводит к снижению функции - генотип GSTT1 (1 / 0), генотип GSTT1 (1 / 1) - дикий тип с нормальной функцией.

Матриксная металлопротеиназа-9, ген - ММР9, локализация - 20q11.2-q13,1, кодируемому белку придают большое значении в развитии ХОБЛ и ЭЛ, полиморфизм (С-1562Т) в промоторной области гена приводит к повышению экспрессии с накоплением соответствующего белка; генотип ММР9 ТТ и генотип ММР9 СТ (гетерозиготное носительство) с нарушенной функцией, генотип ММР9 СС - дикий тип с нормальной функцией.

Цитохром Р450 (кумарин-7-гидроксилаза), ген CYP2А6, локализация - 19p13.2, фаза детоксикации: метаболизм 60-80 \% никотина, ароматических углеводородов. Замена Leu160His (479T / А) приводит к снижению активности фермента. Индивидуумы с мутантными аллелями с меньшей вероятностью будут зависимыми курильщиками, а курящие потребляют меньшее количество сигарет. Генотипы CYP2A6*1 / *2, CYP2A6*2 /*2 - с нарушенной функцией, генотип СYР2А6*1 / *1 - дикий с нормальной функцией.
Ариламин-N-ацетилтрансфераза, ген - NAT2, локализация - 8p21.3-23.1, II фаза детоксикации: ацетилирование ариламинов и др. ксенобиотиков. Ряд аминокислотных замен (комбинации 7 точковых мутаций), приводит к снижению активности ацетилирования.

Генотипы: NAT2 RR - быстрый ацетиляторный статус, NAT2 RS - быстрый ацетиляторный статус, NAT2 SS - медленный ацетиляторный статус.

Предполагалось оценить независимое и совместное влияние изученных генетических маркеров во взаимодействии с фактором курения на относительный риск развития болезни, а также на клинические особенности и сроки манифестации ХОБЛ у больных (применение промежуточного фенотипа).

С применением методов молекулярной генетики были обследованы мужчины славянского происхождения, жители Сант-Петербурга, длительно наблюдавшиеся в НИИ пульмонологии (от 7 до 25 лет) с четко верифицированными диагнозами. Курение в анамнезе было у 100 \% обследованных. Курильщиков с ХОБЛ в этой группе было 72 человека с заболеванием средней (35\%) и тяжелой $(65 \%)$ степени; группу инвалидности не ниже 2-й имели 60 \% больных, из них 80 \% получили инвалидность в трудоспособном возрасте. Средний возраст $-56,35 \pm 1,33$ года. Средний возраст манифестации болезни $42,21 \pm 1,69$ года, средний стаж курения до начала болезни $-24,66 \pm 1,87$ пачек / лет.

В группу курильщиков табака без хронических болезней органов дыхания (БОД) и других тяжелых сопутствующих заболеваний отбирались лица старше 40 лет (средний возраст - 51,11 \pm 1,41 года), со стажем курения $\geq 20$ пачек / лет (средний стаж курения $-25,97 \pm 2,48$ пачек/лет). Обследованные в этой группе злостные курильщики без БОД, как и больные ХОБЛ, имели в основном рабочие специальности, при этом начальное образование до 5 классов школы получили 12,8 \% (vs 19,6 \% при ХОБЛ) и 23,4\% страдали алкоголизмом (vs 28,5\% при ХОБЛ). Таким образом, обследованные злостные курильщики с ХОБЛ и злостные курильщики без БОД имели сопоставимые условия трудовой деятельности (лица рабочих специальностей без официальных профессиональных вредностей), социально-экономический статус и не имели кровного родства. Группы практически не отличались по возрасту и анамнезу курения.

Группу курильщиков с ХНБ составили 38 больных в возрасте $51,47 \pm 2,11$ года со средним возрастом манифестации болезни $37,23 \pm 2,16$ года. Стаж курения до болезни - 26,95 $\pm 2,54$ пачек / лет. Лица рабочих специальностей (без профессиональных вредностей) составили 41,8 \%, начальное образование имели 3,6 \% больных ХНБ, алкоголизмом страдали $8,8 \%$, т. е. курильщики с ХНБ имели более благоприятный, по сравнению с другими обследованными, социальный статус. Более $1 / 2$ всех обследованных курильщиков подвергались переохлаждению на работе.

Полученные результаты свидетельствовали о важной роли генов GSTM1, GSTT1, MMP9, CYP2A6 
и NAT2, продукты которых участвуют в системах детоксикации и протеолиза-антипротеолиза в формировании наследственной предрасположенности к ХОБЛ у курильщиков табака. При анализе достоверно значимая ассоциация с ХОБЛ была выявлена для генотипа GSTM1 (0 / 0) и отмечено накопление генотипов GSTT1 (0 / 0), MMP9 (CT) и NAT2 (RS). При этом в группе злостных курильщиков без БОД все изученные генотипы с измененной функцией кодируемого белка встречались реже, чем при ХОБЛ и ХНБ, а частота генотипа GSTM1 (0 / 0) оказалась ниже популяционной.

В группе ХОБЛ достоверно чаще, чем у злостных курильщиков без БОД, встречалось сочетание 2 неблагоприятных генотипов и только при ХОБЛ было отмечено сочетание 3 неблагоприятных генотипов.

При анализе ген-генного взаимодействия была выявлена роль кумулятивного вклада изученных генных вариантов в развитии ХОБЛ у курильщиков. Генотип GSTM1 (0 / 0) являлся значимым для формирования ХОБЛ у курильщиков табака, повышая риск заболевания почти в 3 раза. Действие фактора MMP9 (CT) слабее, и OR не достигал статистической достоверности, но в то же время являлся потенцирующим для носителей генотипа GSTM1 (0 / 0), т. к. у курильщиков с комбинацией генотипов GSTM1 (0 / 0) / MMP9 (СТ) риск ХОБЛ увеличивался в 7,7 раза по сравнению с носителями 2 нормальных генотипов. Показано, что сочетание 2 неблагоприятных генотипов GSTM1 (0 / 0) и MMP9 (CT) встречалось чаще в группе ХОБЛ чем в группе курильщиков без БОД и в группе ХНБ.

Таким образом было показано, что сочетание полиморфизма, который приводит к полной потере активности фермента II фазы детоксикации ксенобиотиков (GSTM1 0 / 0) и полиморфизма, который приводит к гиперэкспрессии металлопротеиназы, участвующей в деструкции и ремоделировании легочной паренхимы (ММР9 СТ), существенно увеличивает относительный риск развития ХОБЛ по сравнению с носителями 2 нормальных генотипов.

Результаты исследования демонстрировали и определенную роль генных вариантов СYP2A6 и NAT2 при формировании наследственной предрасположенности к ХОБЛ у курильщиков табака. Так как достоверно значимых ассоциаций полиморфизмов этих генов с ХОБЛ в работе не выявлено, было применено исследование с промежуточными фенотипами - сроками начала заболевания, интегральным показателем ОФВ 1 и жизненной емкости легких (ЖЕЛ). Показано, что генотип RR и RS - быстрое ацетилирование по гену NAT2 - является фактором, предрасполагающим к ранней манифестации ХОБЛ; аналогичные данные о сроках заболевания выявлены у больных с бронхиальной астмой $[90,91]$.

Получены данные о том, что индивидуумы, обладающие аллелями RR и RS гена NAT2, не только в более раннем возрасте (до 50 лет), но и с меньшим стажем курения заболевали ХОБЛ. Этот эффект становился еще более выраженным в группе пациентов с сочетанным генотипом, определяющим фенотип слабого метаболизера по гену СYР2А6 и быстрого ацетилятора по гену NAT2. Среди лиц с ранней манифестацией заболевания такая комбинация генотипов по 2 генам была представлена в 12,5\% случаев, тогда как при более позднем дебюте не встретилась ни разу. Таким образом, можно считать, что полиморфные аллели генов CYP2A6 и NAT2 не являются основными генетическими факторами риска развития ХОБЛ, но способны модифицировать ее течение в сторону более раннего начала заболевания.

Не выявлено ассоциаций между носительством полиморфных аллелей генов GSTM1, GSTT1, MMP9 и данными, характеризующими анамнез и дебют ХОБЛ и ХНБ.

У больных ХОБЛ с нуль-генотипом глутатион-Sтрансферазы M1 выявлено достоверное снижение показателей ЖЕЛ и ОФВ 1 в возрасте 56-65 лет по сравнению с носителями дикого генотипа; у пациентов с ХОБЛ с фенотипами слабого метаболизера по гену CYP2A6 (CYP2A6*1 / *2, *2 / *2) и быстрого ацетилятора по гену NAT2 (RR, RS) определены наиболее высокие показатели ЖЕЛ и ОФВ 1 в возрасте 46-55 лет.

В целом в результате комплекса исследований, проведенного у больных ХОБЛ, ХНБ и их семей, случайной выборки жителей Санкт-Петербурга и их семей, а также у курильщиков без БОД и другой тяжелой сопутствующей патологии (всего 1728 человек), были получены данные о 45 фенотипах (11 генетических маркеров, 18 морфофункциональных признаках), 9 основных показателях ФВД, об интенсивности курения. Использован многофакторный анализ для биологических систем - статусметрия и было показано, что по генетическому профилю ХОБЛ и ХНБ разные заболевания. За длительный период наблюдения в НИИ пульмонологии ни один пациент с верифицированным диагнозом хронического необструктивного (простого) бронхита не перешел в группу пациентов с ХОБЛ. Такое заключение может подтверждать гипотезу о том, что ХОБЛ, вероятно, не является самостоятельным заболеванием, а отражает стадии развития ЭЛ.

Для ХОБЛ как мультифакторного заболевания комбинации генотипов играли бо́льшую роль, чем отдельно взятые генотипы, что и было показано в настоящем исследовании. Таким образом, был сделан еще один шаг в развитии предиктивной медицины, направленной на выявление и анализ генов предрасположенности к наиболее частым многофакторным болезням [92]. Поиск новых генов предрасположенности к ХОБЛ и ЭЛ активно продолжается.

Комплексные подходы с кооперацией исследований, применением новых генетических технологий, в т. ч. дальнейших работ по интеграции методов генной экспрессии и генной вариабельности, несомненно, ускорят и облегчат этот процесс. Приведенные схемы подчеркивают необходимость комплексного подхода в изучении генетики ЭЛ и ХОБЛ с учетом факторов, о которых шла речь выше. 


\section{Литература}

1. Пузырев В.П. Генетика мультифакториальных заболеваний между прошлым и будущим. Мед. генетика 2003; 12: 498-508.

2. Silverman E.K., Mosley J.D., Palmer L.J. et al. Genome-wide linkage analysis of severe, early-onset chronic obstructive pulmonary disease: airflow obstruction and chronic bronchitis phenotypes. Hum. Mol. Genet. 2002; 11: 623-632.

3. Silverman E.K., Palmer L.J., Mosley J.D. et al. Genomewide linkage analysis of quantitative spirometric phenotypes in severe early-onset chronic obstructive pulmonary disease. Am. J. Hum. Genet. 2002; 70: 1229-1239.

4. Palmer L.J., Celedon J.C., Chapman H.A. et al. Genomewide linkage analysis of bronchodilator responsiveness and post-bronchodilator spirometric phenotypes in chronic obstructive pulmonary disease. Hum. Mol. Genet. 2003; 12: $1199-1210$

5. DeMeo D.L., Celedon J.C., Lange C. et al. Genome-wide linkage of forced mid-expiratory flow in chronic obstructive pulmonary disease. Am. J. Respir. Crit. Care Med. 2004; 170: 1294-1301.

6. Silverman E.K., Chapman H.A., Drazen J.M. et al. Genetic epidemiology of severe, early-onset chronic obstructive pulmonary disease: risk to relatives for airflow obstruction and chronic bronchitis. Am. J. Respir. Crit. Care Med. 1998; 157: $1770-1778$.

7. Malhotra A., Peiffer A.P., Ryujin.DT. et al. Further evidence for the role of genes on chromosome 2 and chromosome 5 in the inheritance of pulmonary function. Am. J. Respir. Crit. Care Med. 2003; 168: 556-561.

8. DeMeo D.L., Mariani T.J., Lange C. et al. The SERPINE2 gene is associated with chronic obstructive pulmonary disease. Am. J. Hum. Genet. 2006; 78: 253-264.

9. Spira A., Beane J., Pinto-Plata V. et al. Gene expression profiling of human lung tissue from smokers with severe emphysema. Am. J. Respir. Cell. Mol. Biol. 2004; 31: 601-610.

10. Hersh C.P., DeMeo D.L., Silverman E.K. Chronic obstructive pulmonary disease. In: Silverman E.K., Shapiro S.D., Lomas D.A., Weiss S.T. (eds.). Respiratory genetics. New York: Hodder Arnold; 2005. 253-296.

11. Shapiro S.D. Transgenic and gene-targeted mice as models for chronic obstructive pulmonary disease. Eur. Respir. J. 2007; 29: 375-378.

12. Zhu G., Warren L., Aponte J. et al. The International COPD Genetics Network (ICGN) Investigators, Anderson W.H., Lomas D.A., Silverman E.K., Pillai S.G. The SERPINE2 gene is associated with chronic obstructive pulmonary disease in two large populations. Am. J. Respir. Crit. Care Med. 2007; 176: 167-173.

13. Palmer L.J., Celedon J.C., Chapman H.A. et al. Genomewide linkage analysis of bronchodilator responsiveness and post-bronchodilator spirometric phenotypes in chronic obstructive pulmonary disease. Hum. Mol. Genet. 2003; 12: 1199-1210.

14. Celedon J.C., Lange C., Raby B.A. et al. The transforming growth factor- $\beta_{1}$ (TGFB1) gene is associated with chronic obstructive pulmonary disease (COPD). Hum. Mol. Genet. 2004; 13: 1649-1656.

15. Silverman E.K., Mosley J.D., Palmer L.J. et al. Genomewide linkage analysis of severe, early-onset chronic obstructive pulmonary disease: airflow obstruction and chronic bronchitis phenotypes. Hum. Mol. Genet. 2002; 11: 623-632.
16. Poller W., Faber J.P., Scholz S. et al. Mis-sense mutation of alpha1-antichymotrypsin gene associated with chronic lung disease. Lancet 1992; 339: 1538.

17. Poller W., Faber J.P., Weidinger S. et al. A leucine-to-proline substitution causes a defective alpha 1-antichymotrypsin allele associated with familial obstructive lung disease. Genomics 1993; 17: 740-743.

18. Ishii T., Matsuse T., Teramoto S. et al. Association between alpha-1-antichymotrypsin polymorphism and susceptibility to chronic obstructive pulmonary disease. Eur. J. Clin. Invest. 2000; 30: 543-548.

19. Sandford A.J., Chagani T., Weir T.D., Pare P.D. Alpha1antichymotrypsin mutations in patients with chronic obstructive pulmonary disease. Dis. Markers 1998; 13: 257-260.

20. Benetazzo M.G., Gile L.S., Bombieri C. et al. Alpha1-antitrypsin TAQ I polymorphism and alpha1-antichymotrypsin mutations in patients with obstructive pulmonary disease. Respir. Med. 1999; 93: 648-654.

21. Ho L.-I., Harn H.-J., Chen C.-J., Tsai N.-M. Polymorphism of the $\beta_{2}$-adrenoceptor in COPD in Chinese subjects. Chest 2001; 120: 1493-1499.

22. Hegab A.E., Sakamoto T., Saitoh W. et al. Polymorphisms of IL4, IL13, and ADRB2 genes in COPD. Chest 2004; 126 : $1832-1839$

23. Joos L., Weir T.D., Connett J.E. et al. Polymorphisms in the beta2-adrenergic receptor and bronchodilator response, bronchial hyperresponsiveness, and rate of decline in lung function in smokers. Thorax 2003; 58: 703-707.

24. Brogger J., Steen V.M., Eiken H.G. et al. Genetic association between COPD and polymorphisms in TNF, ADRB2 and EPHX1. Eur. Respir. J. 2006; 27: 682-688.

25. Matsushita I., Hasegawa K., Nakata K. et al. Genetic variants of human beta-defensin-1 and chronic obstructive pulmonary disease. Biochem. Biophys. Res. Commun. 2002; 291: 17-22.

26. Hu R.C., Xu Y.J., Zhang Z.X. et al. Correlation of HDEFB1 polymorphism and susceptibility to chronic obstructive pulmonary disease in Chinese Han population. Chin. Med. J. (Engl.) 2004; 117: 1637-1641.

27. Wallace A.M., He J.Q., Burkett K.M. et al. Contribution of alpha- and beta-defensins to lung function decline and infection in smokers: an association study. Respir. Res. 2006; 7: 76

28. Hersh C.P., DeMeo D.L., Raby B.A. et al. Genetic linkage and association analysis of COPD-related traits on chromosome 8p. COPD 2006; 3: 189-194.

29. Smith C.A., Harrison D.J. Association between polymorphism in gene for microsomal epoxide hydrolase and susceptibility to emphysema. Lancet 1997; 350: 630-633.

30. Sandford A.J., Chagani T., Weir T.D. et al. Susceptibility genes for rapid decline of lung function in the lung health study. Am. J. Respir. Crit. Care Med. 2001; 163: 469-473.

31. Xiao D., Wang C., Du M.J. et al. Relationship between polymorphisms of genes encoding microsomal epoxide hydrolase and glutathione S-transferase P1 and chronic obstructive pulmonary disease. Chin. Med. J. (Engl.) 2004; 117: 661-667.

32. Demeo D.L., Hersh C.P., Hoffman E.A. et al. Genetic determinants of emphysema distribution in the National Emphysema Treatment Trial. Am. J. Respir. Crit. Care Med. 2007; 176: 42-48.

33. Yoshikawa M., Hiyama K., Ishioka S. et al. Microsomal epoxide hydrolase genotypes and chronic obstructive pulmonary disease in Japanese. Int. J. Mol. Med. 2000; 5: 49-53. 
34. Takeyabu K., Yamaguchi E., Suzuki I. et al. Gene polymorphism for microsomal epoxide hydrolase and susceptibility to emphysema in a Japanese population. Eur. Respir. J. 2000; 15: 891-894.

35. Yim J.J., Park G.Y., Lee C.T. et al. Genetic susceptibility to chronic obstructive pulmonary disease in Koreans: combined analysis of polymorphic genotypes for microsomal epoxide hydrolase and glutathione S-transferase M1 and T1. Thorax 2000; 55: 121-125.

36. Horne S.L., Cockcroft D.W., Dosman J.A. Possible protective effect against chronic obstructive airways disease by the GC2 allele. Hum. Hered. 1990; 40: 173-176.

37. Schellenberg D., Pare P.D., Weir T.D. et al. Vitamin D binding protein variants and the risk of COPD. Am. J. Respir. Crit. Care Med. 1998; 157: 957-961.

38. Ishii T., Keicho N., Teramoto S. et al. Association of Gcglobulin variation with susceptibility to COPD and diffuse panbronchiolitis. Eur. Respir. J. 2001; 18: 753-757.

39. Ito I., Nagai S., Hoshino Y. et al. Risk and severity of COPD is associated with the group-specific component of serum globulin $1 \mathrm{~F}$ allele. Chest 2004; 125: 63-70.

40. Kauffmann F., Kleisbauer J.P., Cambon-De-Mouzon A. et al. Genetic markers in chronic air-flow limitation: a genetic epidemiologic study. Am. Rev. Respir. Dis. 1983; 127: 263-269.

41. Kasuga I., Pare P.D., Ruan J. et al. Lack of association of group specific component haplotypes with lung function in smokers. Thorax 2003; 58: 790-793.

42. Sandford A.J., Chagani T., Weir T.D. et al. Susceptibility genes for rapid decline of lung function in the lung health study. Am. J. Respir. Crit. Care Med. 2001; 163: 469-473.

43. Harrison D.J., Cantlay A.M., Rae F. et al. Frequency of glutathione S-transferase M1 deletion in smokers with emphysema and lung cancer. Hum. Exp. Toxicol. 1997; 16: $356-360$

44. Baranova H., Perriot J., Albuisson E. et al. Peculiarities of the GSTM1 0 / 0 genotype in French heavy smokers with various types of chronic bronchitis. Hum. Genet. 1997; 99: 822-826.

45. Cheng S.L., Yu C.J., Chen C.J., Yang P.C. Genetic polymorphism of epoxide hydrolase and glutathione S-transferase in COPD. Eur. Respir. J. 2004; 23: 818-824.

46. Yim J.J., Park G.Y., Lee C.T. et al. Genetic susceptibility to chronic obstructive pulmonary disease in Koreans: combined analysis of polymorphic genotypes for microsomal epoxide hydrolase and glutathione S-transferase M1 and T1. Thorax 2000; 55: 121-125.

47. He J.-Q., Ruan J., Connett J.E. et al. Antioxidant gene polymorphisms and susceptibility to a rapid decline in lung function in smokers. Am. J. Respir. Crit. Care Med. 2002; 166: 323-328.

48. Ishii T., Matsuse T., Teramoto S. et al. Glutathione S-transferase P1 (GSTP1) polymorphism in patients with chronic obstructive pulmonary disease. Thorax 1999; 54: 693-696.

49. Yim J.J., Yoo C.G., Lee C.T. et al. Lack of association between glutathione S-transferase P1 polymorphism and COPD in Koreans. Lung 2002; 180: 119-125.

50. Yamada N., Yamaya M., Okinaga S. et al. Microsatellite polymorphism in the heme oxygenase- 1 gene promoter is associated with susceptibility to emphysema. Am. J. Hum. Genet. 2000; 66: 187-195.

51. Guenegou A., Leynaert B., Benessiano J. et al. Association of lung function decline with the heme oxygenase-1 gene promoter microsatellite polymorphism in a general population sample: results from the European Community Respiratory
Health Survey (ECRHS), France. J. Med. Genet. 2006; 43: e43.

52. Nakayama K., Kikuchi A., Yasuda H. et al. Heme oxygenase-1 gene promoter polymorphism and decline in lung function in Japanese men. Thorax 2006; 61: 921.

53. Minematsu N., Nakamura H., Tateno H. et al. Genetic polymorphism in matrix metalloproteinase-9 and pulmonary emphysema. Biochem. Biophys. Res. Commun. 2001; 289: 116-119.

54. Zhou M., Huang S.G., Wan H.Y. et al. Genetic polymorphism in matrix metalloproteinase- 9 and the susceptibility to chronic obstructive pulmonary disease in Han population of south China. Chin. Med. J. (Engl.) 2004; 117: 1481-1484.

55. Joos L., He J.Q., Shepherdson M.B. et al. The role of matrix metalloproteinase polymorphisms in the rate of decline in lung function. Hum. Mol. Genet. 2002; 11: 569-576.

56. Chappell S., Daly L., Morgan K. et al. The SERPINE2 gene and chronic obstructive pulmonary disease. Am. J. Hum. Genet. 2006; 79: 184-186 (author reply: 186-187).

57. Juul K., Tybjaerg-Hansen A., Marklund S. et al. Genetically increased antioxidative protection and decreased chronic obstructive pulmonary disease. Am. J. Respir. Crit. Care Med. 2006; 173: 858-864.

58. Young R.P., Hopkins R., Black P.N. et al. Functional variants of antioxidant genes in smokers with COPD and in those with normal lung function. Thorax 2006; 61: 394-399.

59. Guo X., Lin H.M., Lin Z. et al. Surfactant protein gene A, B, and $\mathrm{D}$ marker alleles in chronic obstructive pulmonary disease of a Mexican population. Eur. Respir. J. 2001; 18: 482-490.

60. Seifart C., Plagens A., Brodje D. et al. Surfactant protein B intron 4 variation in German patients with COPD and acute respiratory failure. Dis. Markers 2002; 18: 129-136.

61. Wu L., Chau J., Young R.P. et al. Transforming growth factor-betal genotype and susceptibility to chronic obstructive pulmonary disease. Thorax 2004; 59: 126-129.

62. Su Z.G., Wen F.Q., Feng Y.L. et al. Transforming growth factor-betal gene polymorphisms associated with chronic obstructive pulmonary disease in Chinese population. Acta Pharmacol. Sin. 2005; 26: 714-720.

63. van Diemen C.C., Postma D.S., Vonk J.M. et al. Decorin and TGF-beta1 polymorphisms and development of COPD in a general population. Respir. Res. 2006; 7: 89.

64. Yoon H.I., Silverman E.K., Lee H.W. et al. Lack of association between COPD and transforming growth factor-betal (TGFB1) genetic polymorphisms in Koreans. Int. J. Tuberc. Lung Dis. 2006; 10: 504-509.

65. Ogawa E., Ruan J., Connett J.E. et al. Transforming growth factor-beta1 polymorphisms, airway responsiveness and lung function decline in smokers. Respir. Med. 2007; 101: 938-943.

66. Huang S.-L., Su C.-H., Chang S.-C. Tumor necrosis factorgene polymorphism in chronic bronchitis. Am. J. Respir. Crit. Care Med. 1997; 156: 1436-1439.

67. Sakao S., Tatsumi K., Igari H. et al. Association of tumor necrosis factor alpha gene promoter polymorphism with the presence of chronic obstructive pulmonary disease. Am. J. Respir. Crit. Care Med. 2001; 163: 420-422.

68. Matheson M.C., Ellis J.A., Raven J. et al. Association of IL8, CXCR2 and TNF-alpha polymorphisms and airway disease. J. Hum. Genet. 2006; 51: 196-203.

69. Higham M.A., Pride N.B., Alikhan A., Morrell N.W. Tumour necrosis factor-alpha gene promoter polymorphism in chronic obstructive pulmonary disease. Eur. Respir. J. 2000; 15: $281-284$. 
70. Ishii T., Matsuse T., Teramoto S. et al. Neither IL-1beta, IL-1 receptor antagonist, nor TNF-alpha polymorphisms are associated with susceptibility to COPD. Respir. Med. 2000; 94: 847-851.

71. Patuzzo C., Gile L.S., Zorzetto M. et al. Tumor necrosis factor gene complex in COPD and disseminated bronchiectasis. Chest 2000; 117: 1353-1358.

72. Ferrarotti I., Zorzetto M., Beccaria M. et al. Tumour necrosis factor family genes in a phenotype of COPD associated with emphysema. Eur. Respir. J. 2003; 21: 444-449.

73. Chierakul N., Wongwisutikul P., Vejbaesya S., Chotvilaiwan K. Tumor necrosis factor-alpha gene promoter polymorphism is not associated with smoking-related COPD in Thailand. Respirology 2005; 10: 36-39.

74. Hegab A.E., Sakamoto T., Saitoh W. et al. Polymorphisms of TNF-alpha, IL1-beta, and IL1RN genes in chronic obstructive pulmonary disease. Biochem. Biophys. Res. Commun. 2005; 329: 1246-1252.

75. Jiang L., He B., Zhao M.W. et al. Association of gene polymorphisms of tumour necrosis factor-alpha and interleukin13 with chronic obstructive pulmonary disease in Han nationality in Beijing. Chin. Med. J. (Engl.) 2005; 118: 541-547.

76. Seifart C., Plagens A., Dempfle A. et al. TNF-alpha, TNFbeta, IL-6, and IL-10 polymorphisms in patients with lung cancer. Dis. Markers 2005; 21: 157-165.

77. Ruse C.E., Hill M.C., Tobin M. et al. Tumour necrosis factor gene complex polymorphisms in chronic obstructive pulmonary disease. Respir. Med. 2007; 101: 340-344.

78. Hersh C.P., DeMeo D.L., Silverman E.K. Genetics of Emphysema. Proc. Am. Thorac. Soc. 2008; 5: 486-493.

79. Wilk J.B., Walter R.E., Laramie J.M. et al. Framingham Heart Study genome-wide association: results for pulmonary function measures. BMC Med. Genet. 2007; 8: S8.

80. Hersh C.P., DeMeo D.L., Lange C. et al. Attempted replication of reported chronic obstructive pulmonary disease candidate gene associations. Am. J. Respir. Cell Mol. Biol. 2005; 33: 71-78.

81. Bell B., Rose C.L., Damon H. The Normative Aging Study: an interdisciplinary and longitudinal study of health and aging. Aging. Hum. Dev. 1972; 3: 5-17.

82. Hirschhorn J.N., Altshuler D. Once and again-issues surrounding replication in genetic association studies. J. Clin. Endocrinol. Metab. 2002; 87: 4438-4441.

83. Ioannidis J.P., Ntzani E.E., Trikalinos T.A. ContopoulosIoannidis DG. Replication validity of genetic association studies. Nat. Genet. 2001; 29: 306-309.

84. Colhoun H.M., McKeigue P.M., Davey Smith G. Problems of reporting genetic associations with complex outcomes. Lancet 2003; 361: 865-872.

85. Hersh C.P., DeMeo D.L., Lazarus R. et al. Genetic association analysis of functional impairment in chronic obstructive pulmonary disease. Am. J. Respir. Crit. Care Med. 2006; 173: 977-984.

86. Celli B.R., Cote C.G., Marin J.M. et al. The body-mass index, airflow obstruction, dyspnea, and exercise capacity index in chronic obstructive pulmonary disease. N. Engl. J. Med. 2004; 350: 1005-1012.
87. Ito I., Nagai S., Handa T. et al. Matrix metalloproteinase-9 promoter polymorphism associated with upper lung dominant emphysema. Am. J. Respir. Crit. Care Med. 2005; 172: 1378-1382.

88. Fishman A., Martinez F., Naunheim K. et al. A randomized trial comparing lung-volume-reduction surgery with medical therapy for severe emphysema. N. Engl. J. Med. 2003; 348: 2059-2073.

89. Kelleher C.M., Silverman E.K., Broekelmann T. et al. A functional mutation in the terminal exon of elastin in severe, early-onset chronic obstructive pulmonary disease. Am. J. Respir. Cell Mol. Biol. 2005; 33: 355-362.

90. Вавилин В.А., Макарова С.И., Ляхович В.В., Гавалов С.М. Ассоциация полиморфных генов ферментов биотрансформации ксенобиотиков с предрасположенностью к бронхиальной астме у детей с наследственной отягощенностью и без таковой. Генетика 2002; 38 (4): $539-545$.

91. Сиделева О.Г. Полиморфные аллели генов, ассоциированные с патогенезом атопической формы бронхиальной астмы у жителей северо-запада России: Автореф. дис. ... канд. биол. наук. СПб.; 2002.

92. Баранов В.С., Баранова Е.В., Иващенко Т.Э., Асеев М.В. Геном человека и гены "предрасположенности" (Введение в предиктивную медицину). СПб.: Интермедицина; 2000.

93. Пузырев В.П., Севостьянова Н.В., Фрейдин М.Б., Огородникова Л.М. Особенности репаративного синтеза ДНК и полиморфизма генов ферментов биотрансформации ксенобиотиков у больных раком легкого. Пульмонология 2005; 1: 11-15.

94. Пузырев В.П., Сеитова Г.Н., Букреева Е.Б. и др. Роль полиморфизма в промоторной области гена TNF в развитии хронической обструктивной болезни легких. Бюл. Сиб. Мед. 2004; 3 (2): 29-33.

95. Янбаева Д.Г. Ассоциаиции полиморфных вариантов генов ферментов биотрансформации ксенобиотиков, протеолиза-антипротеолиза и цитокинов с хронической обструктивной болезнью легких: Автореф. дис. ... канд. биол. наук. Уфа; 2004.

96. Ахмадишина Л.3. Полиморфизм генов ферментов монооксигеназной системы и антиоксидантной защиты у больных хроническими заболеваниями дыхательной системы в республике Башкортостан. Уфа; 2004.

97. Байнак О.В. Клинико-генетические особенности формирования хронической обструктивной болезни легких в республике Башкортостан. Автореф. дис. ... канд. мед. наук. Уфа; 2006.

98. Степанищева Л.С., Игнатова Г.Л. Анализ причин, влияющих на возникновение и развитие ХОБЛ у работников машиностроительных предприятий (предварительные результаты). Пульмонология 2005; 4: 11-15.

\section{Информация об авторе}

Ивчик Татьяна Васильевна - д. м. н., ведущий научный сотрудник отдела молекулярно-генетических технологий НИЦ СПбГМУ им. акад. И.П.Павлова. 